Número 29/ Julio 2009

\title{
¿POR QUÉ LAS BITÁCORAS ELECTRÓNICAS (BLOGS) SE USAN POCO PARA ESTUDIAR CIENCIAS FÍSICO-MATEMÁTICAS?
}

\begin{abstract}
Vicente Torres Zúñiga
vicentz@gmail.com

Centro de Ciencias Aplicadas y desarrollo Tecnológico

Universidad Nacional Autónoma de México

\section{RESUMEN}

A pesar que los blogs son una tecnología Web 2.0 versátil, económica y fácil de utilizar en una materia sobre ciencias y para popularizar temas científicos. Por su cuenta, los hispanohablantes utilizan muy poco estos sitos web para estudiar o reforzar materias de las áreas físicomatemáticas. Presentamos un estudio basado en encuestas, montadas en un blog estable y con buen prestigio, el cual cuenta con altos índices de audiencia. Mostramos el modelo de edad, genero y nacionalidad de los cibernautas, también demostramos el gran interés de los usuarios sobre temas científicos, observamos que el nivel de participación en las encuestas es similar al llamado modelo "90.9.1" que describen sitios web más robustos como la Wikipedia.
\end{abstract}

\section{PALABRAS CLAVE:}

Blogs, popularización de la ciencia, TIC en el aula, estrategias de comunicación.

\begin{abstract}
Blogs are a versatile, cheap, and easy to handle Web 2.0 technology suitable to enhance classes and popularization of science. However, Spanish speakers, hardly apply the weblogs to study or complement a class in the physics, mathematics, or in related areas. This is demonstrated via a serial of pools that are attached in a stable and good-well-know blog, which present high rating in the audience. It is presented a model about the age, gender and nationality of normal readers, who present a remarkable interest in science themes. The participation statistics are in agreed with the called model "90:10:1", the same model that describe websites more robust like Wikipedia.
\end{abstract}

\section{KEYWORDS:}

Blogs, science popularization, ICT in the classroom, communication strategies 


\section{Introducción.}

La popularidad y versatilidad de los blogs han atraído la atención de los investigadores y educadores en los últimos años. Las páginas Web llamadas bitácoras electrónicas, las cuales también son conocidas como blogs o weblogs, son un fenómeno social en Internet en amplia expansión. Por ejemplo, se calcula que en español hay más de 80,509 bitácoras especializadas con más de tres posts por semana y más de 5,000 clics por mes, esto es 24.3 veces menos que las bitácoras escritas en ingles con similar actividad y trafico, respectivamente [1]. Además, estos sitios electrónicos pueden ser una fuente de noticias, de promoción comercial o de corte puramente artístico, con uno o varios autores; los blogs tratan muy diversos temas: espectáculos, tecnología, deportes, entre otros. Pese a la gran popularidad de los blogs, son pocas las bitácoras electrónicas que se especializan en temas de educación y ciencia, especialmente sobre física, matemáticas, química y áreas afines; escritos en español. Por ejemplo, la asociación espiral calcula que hay más de $\mathbf{6 8 3}$ bitácoras dedicadas a la educación [2], mientras que los blogs de cine son casi 1.7 veces más y los blogs dedicados al humor representan 2.2 veces más que los blogs educativos [3]. Es decir, los blogs educativos en español son un medio emergente, que apenas empezamos conocer y aprovechar adecuadamente como medio de comunicación masivo.

Son muchos los trabajos donde se afirman las ventajas pedagógicas y formativas de los blogs. Por ejemplo, el fomento al aprendizaje cooperativo [4,5]; la motivación para leer y escribir [6,7]; el estimulo para aprender a encontrar, organizar y compartir información [8]; además de tales beneficios técnico-académicos, los blogs promueven la autoestima $[9,10]$. Más aún, son varias las referencias que muestran el éxito de los blogs en clases de historia, literatura y civismo [4-7,11]. Sin embargo, son pocos los estudios académicos sobre el uso y tendencias de los blogs dedicados a fomentar el aprendizaje de materias del área físico-matemáticas e ingenierías; especialmente en idioma español.

El objetivo de esta contribución es mostrar el perfil y los usos principales de los cibernautas de un blog de divulgación de la física. Presentamos los resultados de una serie de estadísticas de conexión de los cibernautas y las respuestas encuestas on-line sobre el uso de blogs, las preguntas pueden ser contestadas por cualquier visitante al blog llamado El Tao de la Física (http://vicente1064.blogspot.com), el cual es un sitio Web enfocado a fomentar y popularizar los temas de física, matemáticas, educación y áreas circundantes en idioma español. Los resultados muestran que los cibernautas aficionados a los temas científicos aprenden principalmente en Internet; no obstante, en nuestro estudio encontramos que se utilizan poco los blogs para aprender y complementar una clase de ciencias, los cibernautas prefieren la Wikipedia o medios tradicionales para estudiar, como los libros de texto.

El presente articulo cuenta con la siguiente estructura. En la Sección Dos mencionamos sobre qué es un blog, mencionamos brevemente su historia y su tendencia. Después en la Sección Tres describimos la metodología empleada para hacer las encuestas, la mecánica para obtener los resultados y las fuentes de error en este estudio. En la Sección Cuatro se presentan los resultados de esta investigación. En la Sección Cinco mostramos la interpretación y discusión de los resultados. En la Sección Seis mostramos las conclusiones. Finalmente, mostramos las referencias de utilizadas en este trabajo. 


\section{2. ¿Qué es una bitácora electrónica?}

Un blog, o en español bitácora, es un sitio Web periódicamente actualizado que recopila cronológicamente entradas o posts, textos de uno o varios autores, apareciendo primero el post más reciente, pero el autor conserva siempre la libertad de dejar publicado lo que crea pertinente.

Habitualmente, en cada artículo de un blog, los lectores pueden escribir sus comentarios y el autor darles respuesta, de forma que es posible establecer un diálogo entre los visitantes y el autor. No obstante, el autor decide que comentarios se mostraran en su bitácora, pues las herramientas Web 2.0 permiten diseñar blogs en los cuales no todos los internautas puedan participar. El uso o tema de cada blog es particular, los hay de tipo personal, empresarial, tecnológico, educativo (llamados edublogs), etcétera.

Por otro lado, El diseño de los blogs presenta una estructura básica fácil de reconocer, la cual consiste en los siguientes elementos:

1) Una cabecera. Donde se presenta el nombre del blog y un texto alusivo a la misión del blog o un slogan. La cabecera suele ser un hipervínculo a la página principal del blog.

2) Un cuerpo principal. Aquí se muestran los posts, los cuales pueden contar con texto, imágenes, video, o interfaces de audio. En el cuerpo se muestra el titulo de cada post, el autor, y la fecha de publicación.

3) Una columna vertical, lateral al cuerpo principal. En esta región se colocan herramientas adicionales de navegación, una dirección de correo electrónico, un índice de temas, los últimos posts publicados, etcétera.

Con todo, existe flexibilidad en el diseño y estructura de los blogs por lo que hay varias versiones de la anterior estructura; pero son fáciles de identificar los weblogs frente a otros sitios Web tradicionales de la llamada Web 1.0 [12].

Al hablar del origen de los weblogs o blogs, las opiniones apuntan a enmarcarlos dentro de una evolución histórica a partir de aquellas páginas Web que comenzaron a recibir comentarios de los usuarios, los que a su vez los complementaban con enlaces hacia otros sitios [13]. En 1993 aparecen los primeros blogs como un listado de sitios electrónicos y sus hipervínculos eran acompañados de un breve comentario. Ya para 1996 se crean las primeras compañías que alojan blogs que permitían comentarios. En diciembre de 1997: Jorn Barger acuña el término weblog en la acepción que hoy conocemos. En el Año 1999, la empresa Blogger comienza a hospedar a sus primeros blogs. A partir del año 2000 el fenómeno de los blogs se masifica, aparecen nuevos servicios para edición y alojamiento como Bitacoras.com o WordPress, entre otros. Pronto los blogs comienzan a ganar numerosos adeptos y autores por todo el mundo [14].

Las últimas encuestas y estudios del desarrollo y utilización de blogs nos indican que son un fenómeno en crecimiento. Cada vez hay más blogs, hoy ya son más de 200 millones de blogs registrados. Sin embargo, se actualizan al menos una vez a la semana cerca de 20 millones de blogs [15]. El tema de género muestra cierta equidad en los blogs: los escritores de blogs son $66 \%$ hombres y $34 \%$ mujeres. Por otro lado, los blogs dedicados a la ciencia y educación tienen una 
representación baja en comparación con los blogs sobre vida y estilo. Mientras que los weblogs escritos en español tienen una representación muy pequeña: del conjunto total de blogs, el $3 \%$ está escrito en español, mientras que aproximadamente el $36 \%$ en ingles y $37 \%$ en japonés. Es decir, son pocos los blogs dedicados a temas de ciencia y educación, y escritos en español.

Escritos en español, los usos y clases de los blogs son diversos, pero poco analizados. Por lo cual se requiere una observación cuidadosa del desarrollo y empleo de estos sitios electrónicos, especialmente de los blogs con objetivos académicos y de fomento a la educación.

\section{Sobre este estudio}

Para este trabajo deseábamos analizar las principales tendencias de los cibernautas al utilizar los blogs para estudiar temas de los primeros semestres o un poco antes de entrar a una carrera universitaria del área físico-matemáticas e ingeniería.

Para ello, se ha diseñado y construido un blog con una imagen juvenil, atractiva y desenfadada. Además, se han escrito contenidos para un blog con características similares a las de mayoría de los blogs escritos por entusiastas profesores, estudiantes y promotores de la popularización de la ciencia. Por ejemplo, entre sus reglas de operación podemos mencionar: el blog es escrito por único autor, el blog no muestra escudos o menciona apoyo institucional, tampoco usa la base de una dirección URL de alguna institución, colegio, o universidad. Finalmente, como la mayoría de los weblogs, para captar audiencia, este proyecto utilizó únicamente menciones en Internet; es decir, el weblog careció de publicidad o menciones en revistas, periódicos o televisión.

De este modo, la audiencia del blog fue obtenida por dos principales medios:

1) Empleando la recomendación de un amigo a otro amigo, la cual se basa en los enlaces de otros blogs al nuestro y apareciendo en páginas especializadas en recomendar noticias y contenidos de Internet. Microsievos.com y Meneme.net, respectivamente, son ejemplos de esta clase de sitios Web.

2) El blog es parte de listas de blogs dedicados principalmente a los temas a la divulgación de la ciencia y de temas educativos, esta clase de blogs son parte de los llamados edublogs (contracción del ingles de las palabras educational-blogs). El sitio Hispaciencia.net es un claro ejemplo, pues muestra la cabecera y unas cuantas líneas de una lista de edublogs inscritos en este servicio automático.

Con el fin de describir a la herramienta Web desde la cual se realizaron las encuestas de este estudio. A continuación, mencionaremos las características del contenido del blog, las cuales son los atractores de una audiencia especializada, en otras palabras, son el nicho de mercado. Después, mencionaremos la trayectoria y escalafones otorgados al sitio Web. Todo ello con el fin de mostrar que el blog es un sitio estable y conocido por un grupo amplio de la población que nos interesa: jóvenes por entrar o en los primeros años de universidad, quienes les concierna la física y las matemáticas. 


\subsection{Sobre el blog El Tao de la Física}

\subsubsection{Nicho del blog.}

El Tao de la Física (http://vicente1064.blogspot.com) contiene anotaciones (posts) sobre temas de educación, física, matemáticas y filosofía de la ciencia, emplea un lenguaje desenfadado, con poca jerga especializada, pero exacto en los conceptos científicos presentados. En caso de necesitar emplear términos especiales se explican y se usan hipervínculos para señalar a una definición complementaria. Utiliza textos apoyado con imágenes, videos, y otros recursos multimedia de la Web 2.0 para presentar temas de física atractivos al público, utiliza un código editorial para guardar la net-etiqueta, de modo de ser una publicación respetuosa del lector y de los derechos de autor correspondientes [17].

\subsubsection{Sobre el diseño del blog.}

Actualmente, para captar la atención de audiencias juveniles y contar con una presentación atractiva para el público general, el blog muestra un diseño basado en un fondo de colores oscuros, donde se resaltan motivos blancos en brillantes amarillos. Con el fin de resaltar los títulos de las anotaciones, se usan cabeceras en tipografía roja; mientras que para el resto del texto se usan letras en negro en un fondo blanco. Del lado derecho de la pantalla, se localiza la barra adicional con un fondo azul, la cual presenta muchas herramientas de comunicación, navegación e imágenes, el lector puede visitar el sitio para ver su estado actual de diseño gráfico en http://vicente1064.blogspot.com.

\subsubsection{Posición en la red y trayectoria}

Deseamos enfatizar que el blog es estable, es un sitio con amplia actividad y cuenta con un buen nombre en el medio. Por ello, es sustancial señalar que por casi más tres años el blog se actualiza en promedio tres veces a la semana, contando ya con más de 1,000 posts en la base de datos. También, que el número de clics en el sitio cuenta con un crecimiento anual constante, que supera ya el medio millón de clics en la historia de la bitácora. Así, la figura 1 presenta la historia de clics en el blog desde enero del 2007 hasta mayo del 2009. Adicionalmente, en el cuadro 1 se muestran los escalafones y niveles más importantes y grandes obtenidos en el blog, los cuales representan el buen nombre del sitio entre la gran cantidad de weblogs en Internet. 


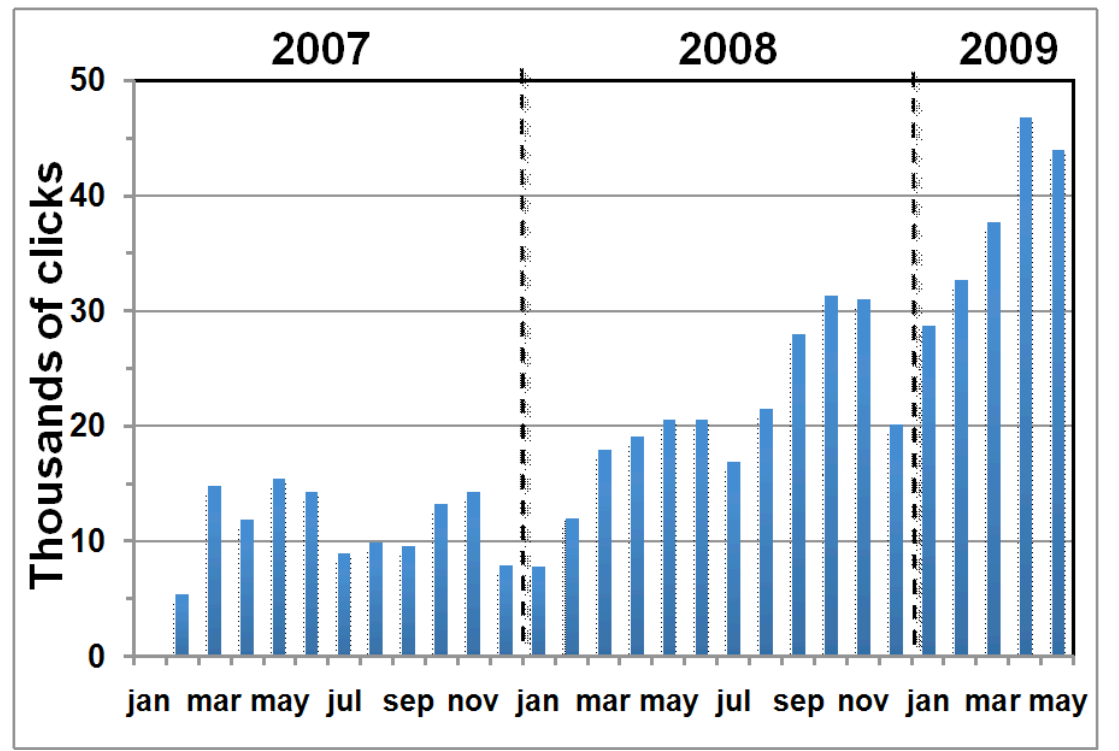

Figura 1. Historia de casi tres años los clics en el blog El Tao de la Física. Anualmente el crecimiento ha sido constante, pero en los meses se ve una variación en los periodos de vacaciones escolares.

Cuadro 1. Principales números y escalafones en la historia del blog "El Tao de la Física". Estas cifras muestran que el blog cuenta con una buena reputación en Internet. Sin embargo, estas cantidades y niveles pueden ser obtenidos por otros blogs de corte editorial similar.

\begin{tabular}{|c|c|c|c|}
\hline Medio o sitio Web & $\begin{array}{l}\text { Nivel o escalafón } \\
\text { máximo obtenido }\end{array}$ & $\begin{array}{l}\text { Fecha de } \\
\text { consulta }\end{array}$ & Notas \\
\hline 1) Technorati.net & $\begin{array}{l}\text { Autoridad 41, por } \\
\text { debajo de casi } \\
100,000 \text { blogs }\end{array}$ & $10 / 04 / 2008$ & $\begin{array}{l}\text { Este sitio es el más popular } \\
\text { y especializado en el tema } \\
\text { de blogs }\end{array}$ \\
\hline $\begin{array}{l}\text { 2) Wikio.com (blogs de } \\
\text { ciencia en español) }\end{array}$ & 19 entre 100 blogs & $5 / 07 / 2008$ & $\begin{array}{l}\text { Sitio segmentado para } \\
\text { blogs en español y de } \\
\text { ciencia }\end{array}$ \\
\hline $\begin{array}{l}\text { 3) Pagerank, servicio de } \\
\text { Google.com }\end{array}$ & 4.0 & $7 / 05 / 2009$ & $\begin{array}{l}\text { Escala logarítmica del valor } \\
\text { de las páginas web, } \\
\text { basado en hiperenlaces al } \\
\text { sitio medido }\end{array}$ \\
\hline 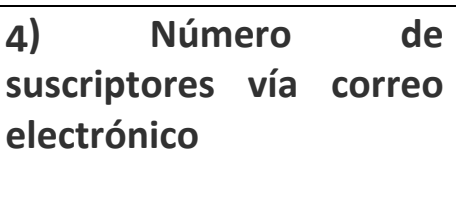 & 747 & $5 / 07 / 2009$ & $\begin{array}{l}\text { Usuarios quienes reciben } \\
\text { la cabecera y primeras } \\
\text { palabras de los posts de } \\
\text { cada día }\end{array}$ \\
\hline $\begin{array}{llr}\text { 5) Número } & \text { de } \\
\text { suscriptores via } & \text { RSS }\end{array}$ & 290 & $10 / 02 / 2009$ & $\begin{array}{l}\text { Usuarios quienes reciben } \\
\text { los }\end{array}$ \\
\hline
\end{tabular}




\begin{tabular}{|l|l|l|l|}
\hline Google Reader & & & automáticamente \\
\hline $\begin{array}{l}\text { 6) Número promedio de } \\
\text { páginas consultadas por } \\
\text { visita }\end{array}$ & 1.7 & $5 / 04 / 2009$ & $\begin{array}{l}\text { En promedio un } \\
\text { cibernauta consulta más } \\
\text { de un post. Se considera } \\
\text { un nivel muy alto que } \\
\text { consulte 2.2 páginas }\end{array}$ \\
\hline
\end{tabular}

\subsection{Mecánica de la implementación de encuestas y estadísticas.}

Utilizamos un servicio independiente y gratuito de encuestas online: Vizu.com, el cual permite crear diversos formatos de encuestas. Por ejemplo, se pueden presentar encuestas donde el Orden de las Respuestas es al Azar (en adelante ORA) o el Orden de las Respuestas es Fijo (en adelante ORF). Esta característica es importante pues existen preguntas que pueden tener un error de sesgo ocasionado por el orden en que se presentan las opciones de respuesta a la pregunta. Además, este servicio de encuestas permite adaptar los colores y fuentes de la encuesta para volverla más atractiva la actividad para el cibernauta.

Luego, cuando un cibernauta accede al blog puede responder a la encuesta, al hacerlo su computadora envía la información al servidor; por su parte, la ordenador servidor envía de regreso los resultados parciales de la encuesta, mediante un gráfico de barras y porcentajes. El sistema impide que se conteste nuevamente la encuesta manteniendo un registro IP de la computadora que solicito el servicio. En este estudio se presentan diferentes encuestas con distinto número de actividad, pero todas por arriba de las 100 participaciones.

Adicionalmente, Para apoyar los resultados obtenidos de las encuestas on-line también se emplearon los servicios de los portales Google Analytics y Sitemeter.com, especialmente para analizar la procedencia de los cibernautas y sus tendencias dentro del weblog.

\subsection{Fuentes de error en las encuestas}

Los resultados en las encuestas son susceptibles a errores metodológicos, por ejemplo:

1) Frente a una pantalla de computadora puede haber más de un usuario contestando una misma encuesta.

2) Una misma persona puede contestar una misma encuesta en varios ordenadores, en diferentes momentos.

Esto significa que se puede presentar un mayor peso específico en la opinión de una persona, lo cual puede alterar la interpretación de los resultados estadísticos. No obstante, consideramos que es baja la probabilidad de que un cibernauta tome tal actitud; de hecho, mientras más personas participen en las encuestas, esta clase de errores de metodología se diluyen. 


\section{Resultados}

En esta sección mostramos los resultados que mejor definen a la audiencia del blog y su actitud frente los blogs como una herramienta para complementar una clase de física, de matemáticas o similar.

En resumen, encontramos que el usuario promedio es estudiante, varón, entre los 15 y los 25 años, que probablemente se conecta desde España o México. Este visitante modelo reconoce la importancia de la ciencia y está tiene mucha actividad en experimentos; utilizan ampliamente la Internet para enterase sobre los temas de ciencia. Sin embargo, Los visitantes modelos del blog usan muy poco los blogs para hacer su tarea, para ello prefieren consultar la Wikipedia o libros. Además, usan principalmente los blogs para investigar por su cuenta.

\subsection{Anatomía de la población: ocupación, genero, edad, nacionalidad}

Ante la pregunta ORA: ¿Te consideras? A) Profesor B) Estudiante. El $\mathbf{2 8 \%}$ se considera profesor, mientras que el $\mathbf{7 2} \%$ se ubica como estudiante, con 143 participaciones. Además, respondieron la pregunta ORA: ¿Soy?: A) Mujer B) Hombre, respondieron 165 cibernautas, con 21\% de mujeres y $\mathbf{7 9 \%}$ de hombres. Mientras que ante las preguntas de orden fijo ORF: ¿Cuál es tu edad?; en la ` 3 encontramos la distribución estadística de las edades de los visitantes, encontramos que los cibernautas tienen una edad entre los 15 y los 25 años, con un total de 233 clics. De acuerdo con Google Analitytics, las computadoras que se conectaron al blog principalmente se encontraban en

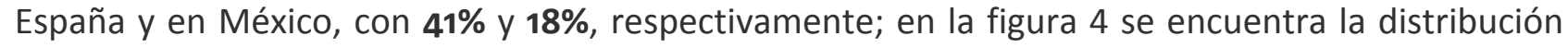
porcentual de los países desde donde accedieron al blog.
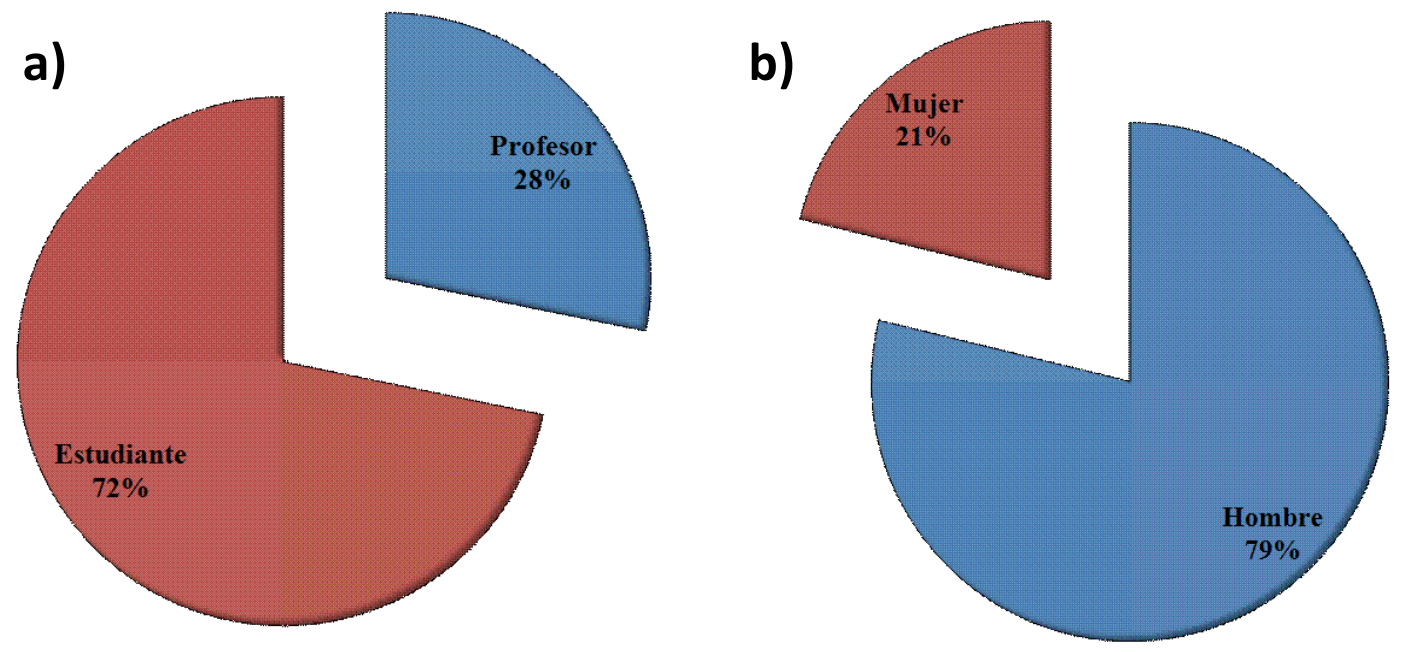

Figura 2. Distribución de ubicación académica y sexo. a) Respuesta a la pregunta de orden al azar: "soy...A) Profesor B) Estudiante". Encontramos que el $28 \%$ de la audiencia se considera profesor, mientras que el $72 \%$ consideran que son estudiantes. b) Respuesta a la pregunta de género de la audiencia del blog. Encontramos que la mayoría de la audiencia es masculina. De modo que 21\% son mujeres, mientras que el $79 \%$ son hombres. 


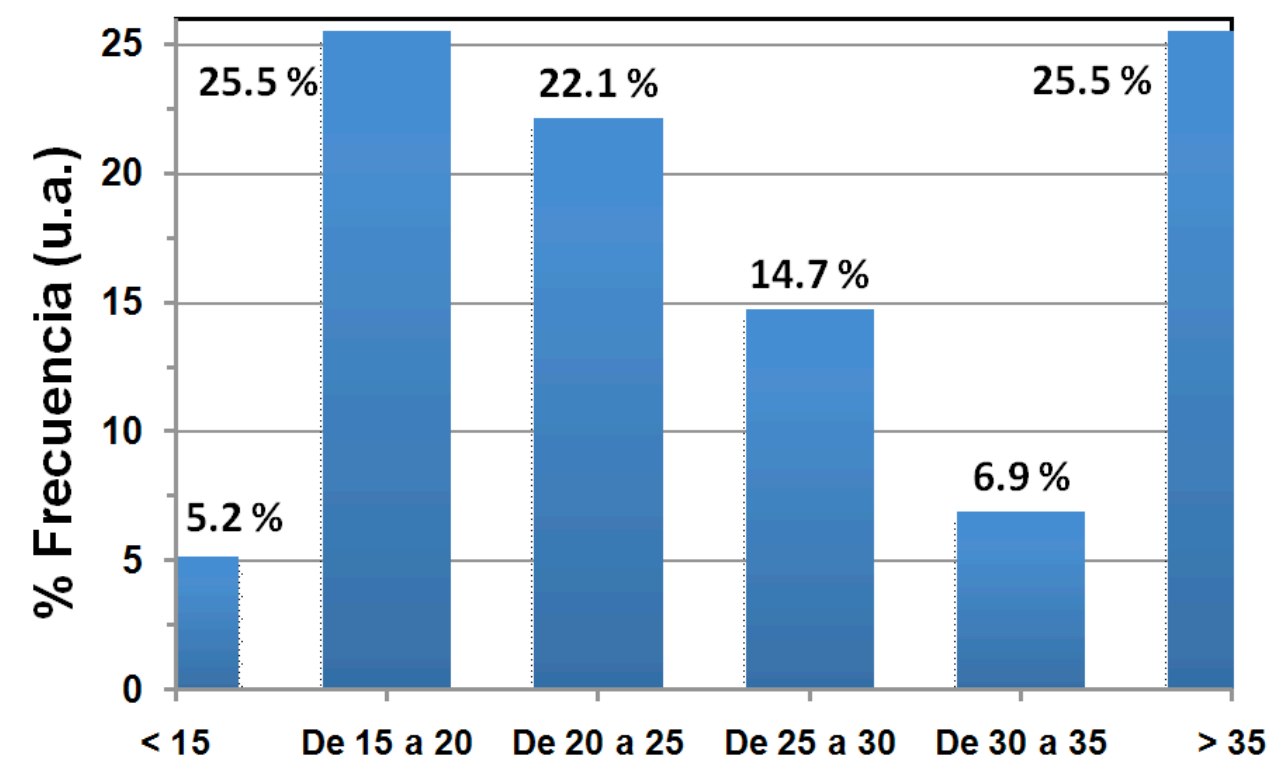

Figura 3. Distribución de edades de los visitantes al blog. Encontramos que la mayoría de los visitantes cuentan con una edad entre los 15 y 25 años, una edad que puede corresponder a estudiantes quienes están por entra a la universidad o se encuentran en sus primeros años de licenciatura.

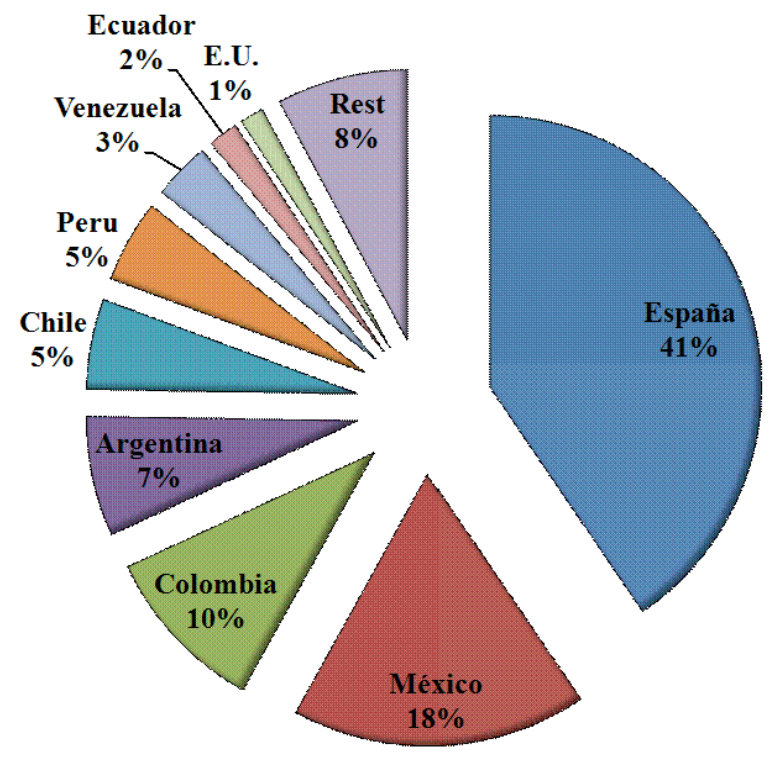

Figura 4. Distribución de las naciones desde donde se conectan los cibernautas al blog. De entre 77 países, España, México y Colombia son las naciones desde donde más visitantes se obtienen.

\subsection{Interés en temas de física-matemáticas}

Se realizaron preguntas para conocer el interés de los visitantes a los temas de física-matemáticos y relacionados con diversas preguntas. A los usuarios se les presento la pregunta ORA: ¿Crees que la física mejora nuestras vidas?: A) Si B) No C) No se, el resultado fue favor del "sí" con el 85.5\% 
de un total de $\mathbf{5 3 1}$ clics. Para la cuestión ORA: ¿Consideras que este blog es útil?: A) No B) Sí, obteniendo un total 102 clics, 90\% respondieron "si". Para la pregunta ORF: ¿Cuándo fue tu último experimento? Encontramos que el $\mathbf{3 8 . 1 \%}$ y $\mathbf{2 8 . 6 \%}$ de los visitantes consideran que en menos de una semana, y entre una semana $y$ un mes han realizado un experimento, respectivamente.

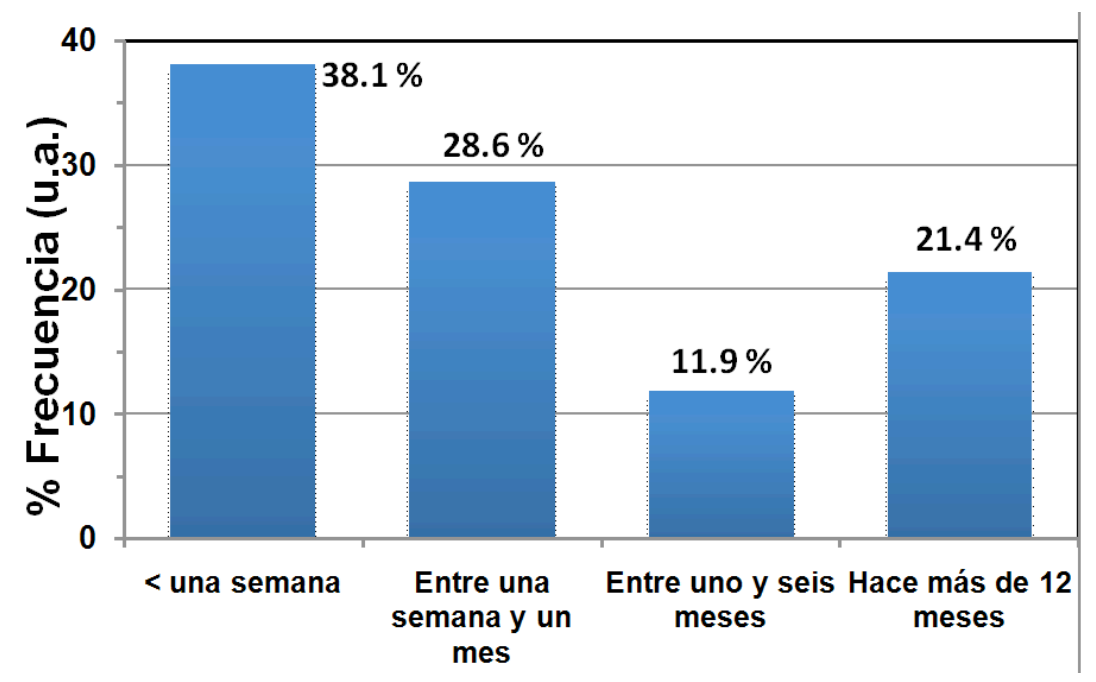

Figura 5. Distribución de la respuesta a la pregunta de orden fijo: Mi último experimento lo hice hace... Encontramos que la mayoría los visitantes del blog consideran que su han realizado un experimento en menos de un mes.

\subsection{Blogs frente a otros medios de información}

Para conocer la posición de los cibernautas ante los blogs como medios herramientas didácticas, usamos la pregunta ORA: Para enterarte de temas de ciencia utilizas principalmente..., donde el medio del Internet domina con $\mathbf{8 0 \%}$ de un total de $\mathbf{1 1 5}$ clics. En la figura 6a se encuentran la distribución para otros medios de comunicación. Sin embargo, ante la pregunta ORF: Para estudiar principalmente uso..., encontramos una preferencia a los blogs del $\mathbf{3} \%$, frente al $\mathbf{3 0} \%$ de la Wikipedia y el $\mathbf{6 7 \%}$ de los libros, de un total de 185 clics; La figura $6 \mathrm{~b}$ muestra la gráfica de la distribución de datos. Entonces, para la pregunta ORF ¿Cuánto usas los blogs para estudiar? Los blogs se usan mucho un $23 \%$, poco $30 \%$ y nada $47 \%$, con un total de 103 clics; en la figura $6 c$ encontramos la gráfica pastel de los datos. Mientras que para la pregunta ORA: Me gustan los blogs científicos para..., la respuesta más aceptada fue para entretenerse con $39 \%$, seguido de investigar por mi cuenta $38 \%$ y atrás la de hacer mi tarea $23 \%$, con un total de 164 clics. 

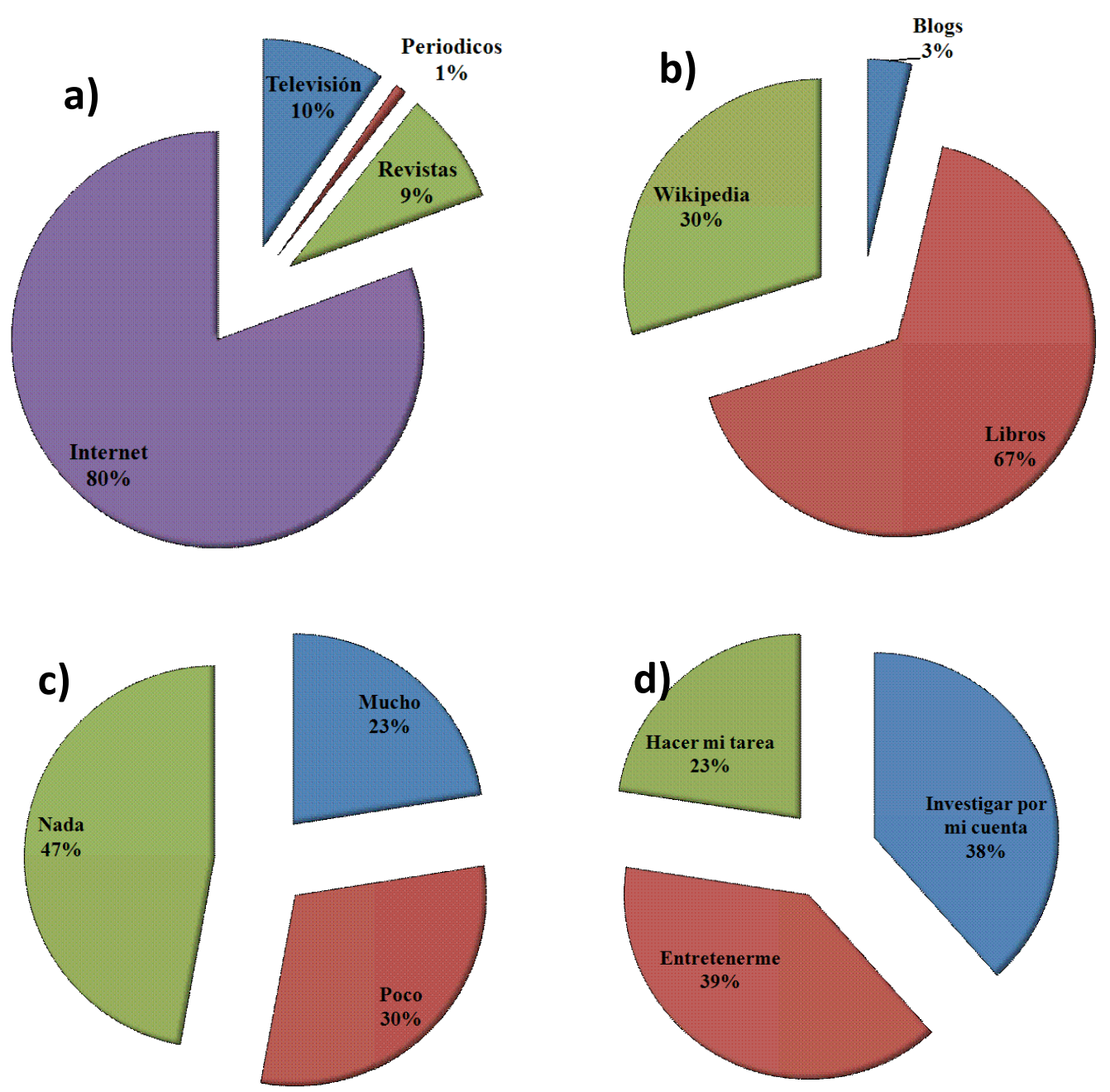

Figura 6. Respuesta sobre los usos de Internet y los blogs para informarse sobre ciencia y hacer trabajos escolares. a) Distribución de la respuesta a la pregunta de opción al azar: "Para enterarme de temas de ciencia utilizas principalmente..." La mayoría de los cibernautas usan Internet para aprender ciencia, después televisión y revistas, otros medios como revistas son poco empleados. b) Estadística de respuesta a la pregunta de orden azarosa: "Para estudiar principalmente uso..."Los cibernautas responden que emplean más los libros, después la Wikipedia y pocas veces los blogs. c) Distribución de la respuesta a la pregunta de orden fijo:" Uso datos de Internet para estudiar". Los visitantes responden que usan los blogs Nada 47\%, Poco 30\%, mientras que solo una fracción de $23 \%$ considera que usan mucho los blogs para estudiar. d) Distribución de la respuesta a la pregunta de orden azaroso:" Me gustan los blogs para..." El 39\% los usa para entretenerse, mientras que 38\% para investigar por su cuenta, sólo una fracción de $23 \%$ usa los blogs para hacer su tarea.

\section{Discusión de los resultados.}

Primero, la trayectoria y el prestigio del blog, además de la considerable cantidad y variedad de contenidos del sitio le brindan un buen nivel de audiencia al blog. Por lo cual, se puede estudiar el comportamiento de estos visitantes frente a un medio especializado en temas de física- 
matemáticas y áreas similares. No obstante, las cifras mostradas pueden ser reproducidas por otro blog. Pues, como lo muestran estudios de mercado en sitios similares, en blogs con más de un redactor, en un mes se pueden hasta alcanzar el millón de clics [15].

Por otro lado, los resultados de las estadísticas y las encuestas son imágenes proyectadas que nos permiten conocer temporalmente y en promedio el comportamiento de los usuarios de un medio de comunicación tan dinámico y flexible como lo es la Internet. Es importante tomar en cuenta que estos modelos pueden cambiar con el tiempo. Pero la composición de la población que participa en las encuestas cambia muy poco, pues en las encuestas participan los usuarios más interesados y activos en el medio. Este fenómeno de participación es llamado el efecto "90.9.1", el cual describe que en las comunidades en Internet (como la Wikipedia.com o Faceboook.com) la población se distribuye como: $1 \%$ usuarios que generan contenido y son muy participativos, $9 \%$ de usuarios que comentan sobre algunos contenidos, y $90 \%$ son usuarios que se limitan a observar, sin comentar o generar contenidos en esa comunidad virtual [18].

De las encuestas, encontramos que la mayoría de los usuarios son varones. Sin embargo, los contenidos están dirigidos tanto para hombres y mujeres. Diversos estudios de matricula muestran que son pocas las mujeres que les interesa y se deciden por seguir una carrera del área físico-matemáticas $[\mathbf{1 5}, \mathbf{1 9}]$. Con todo, se requieren muchos estudios adicionales para confirmar esta tendencia en Internet.

En cuanto a la profesión, estamos interesados en saber si los visitantes se consideran profesores o no. Nuestro objetivo en el blog es el captar la atención de los estudiantes, mientras que los profesores son catalizadores para que el blog obtenga más visitantes estudiantes.

Sobre las edades de los visitantes. Encontramos que la mayoría de nuestros usuarios son jóvenes, por lo cual suponemos que deben usar cotidianamente la computadora y deben contar cierta familiaridad con medios como lo son los blogs. Además, El corte desenfadado de los contenidos permite captar la atención de esta clase de audiencia. Vale la pena señalar que se cuenta con una audiencia amplia de visitantes mayores de 35 años, la cual debemos estudiar con más detalle en futuros trabajos.

Sobre el origen de la conexión. Hay una presencia clara de algunos países hispanohablantes, los cuales bien pueden contar con más conexiones o mejores tarifas, mayor promoción en su sociedad del uso de Internet, más población, o todas las combinaciones de las anteriores en comparación con otras naciones. Este estudio por país no se puede relacionar con el nivel de desarrollo de ciencia o tecnología de cada nación. El presente estudio solamente se puede relacionar con una tendencia sobre el uso de blogs de corte científico en cada estado.

Se han realizado varias encuestas para que los usuarios definan su interés y su grado para involucrarse en los temas principales del blog. Los resultados y la participación en el blog muestran que los visitantes habituales del blog están muy comprometidos con la ciencia. Lo cual los hace idóneos para hacer estudios posteriores sobre el tema y el uso de blogs de esta categoría.

Pese a todos estos datos, lo que representa la médula de esta contribución. Los blogs pueden ser medios que atraen a pocos cibernautas para hacer la tarea y apoyar las labores académicas fuera del aula, la excepción se puede encontrar cuando algún profesor emplea un blog de referencia para apoyar su clase. Para estudiar -por su cuenta- se emplean muy poco los blogs, los 
usuarios prefieren la Wikipedia y los libros, pues los usuarios usan los blogs para entretenerse o para actividades de investigación independiente. Además puede ser que el libro sea la principal herramienta para apoyar una clase de ciencias, pues el uso de blogs $u$ otras herramientas similares sigue siendo emergente entre muchos centros académicos. Esta tendencia en el uso de los blogs se confirma con datos de la población en México: únicamente el $43.5 \%$ de los cibernautas acceden a Internet para realizar tareas escolares [20]. Estos resultados son significativos para diseñar blogs complementarios a libros de texto o la creación de blogs como revistas digitales de divulgación científica, entre otros proyectos didácticos.

Este estudio se puede complementar con investigaciones análogas en bitácoras electrónicas similares, sin necesidad de un apoyo institucional o un presupuesto excesivo, pues las cifras logradas por este blog pueden ser obtenidas por bitácoras electrónicas de corte parecido. Los blogs que mejor pueden llegar a complementar este estudio podrían contar con una temática educativa definida, destinados a poblaciones controladas, y compuestas por estudiantes de ciencias. Por supuesto, también se requieren comparaciones con estudios análogos en otros blogs que se enfoquen temas de humanidades, historia, lenguas y blogs equivalentes.

Por otro lado, además de añadir otros blogs en este estudio, en futuros estudios se deberá profundizar en las respuestas de los visitantes al blog el Tao de la Física, con el fin de abarcar una muestra más representativa y mejorar la interpretación de los resultados, especialmente a las respuestas del uso de blogs para estudiar y el uso del uso de los blogs de corte científicos entre hombres y mujeres.

En la población general, aun existe una gran desconfianza en la información que aparece en los blogs, pues utiliza un formato que resalta a la personalidad. A diferencia de muchas enciclopedias online, donde se resalta el contenido y la personalidad de los redactores es suprimida. Sin embargo, la tendencia puede cambiar drásticamente mientras más blogs especializados en educación, ciencias y temas técnicos o académicos aparezcan en Internet y ganen la confianza de las comunidades educativas, grupos académicos y el público en general.

\section{Conclusiones}

En años recientes, el desarrollo y uso masivo de los servicios de la llamada Web 2.0 han atraído la atención de los profesores e investigadores en educación y comunicación. Por ejemplo, sitios de colaboración de noticias, la Wikipedia y los blogs, por mencionar algunas herramientas populares de Internet. Estos servicios son medios de información cómodos, versátiles y económicos para complementar clases y divulgar la ciencia a amplios sectores de la población.

En particular, los blogs son una vía prometedora de creación de clases trasversales, crítica constructiva y trabajo colaborativo efectivo. Sin embargo, fuera de que se les obligue para cumplir los créditos de una materia, entre los hispanohablantes los blogs son un medio poco empleado para aprender ciencia, aun en grupos con un claro y amplio gusto por la ciencia.

En este trabajo presentamos los resultados de encuestas on-line embebidas en un estable y bien posicionado blog de corte educativo en el área de físico-matemáticas, escrito en español. Los resultados muestran que los blogs son poco empleados para estudiar materias relacionadas a la 
física y las matemáticas, aun en una población modelada como cibernautas varones, entre 20 y 30 años, quienes principalmente se conectan desde España o México, y quienes tienen una experiencia cotidiana y amplio gusto a las ciencias experimentales.

Esperamos que este trabajo desate estudios similares y complementarios del uso de las páginas Web para divulgar la ciencia, de usar los blogs para complementar clases para apoyar el desarrollo científico y el crecimiento las comunidades.

\section{Referencias.}

[1] NITLE: Blog Census consultado en http://www.knowledgesearch.org/census/lang.html, (generado: 17/dic/03; consultado: 2/feb/09)

[2] Blog del premio edublogso9, nota informativa 2/abril/2009 consultado el 12/abril/2009 http://ciberespiral.org/edublogs09/?p=2707

[3] Portal de la blogoteca, generado 10 abril del 2009, consultado el 13 abril de 2009 http://lablogoteca.20minutos.es/

[4] Drexler,Wendy;Dawson, Kara \& Ferdig, Richard E., "Collaborative Blogging as a Means to Develop Elementary Expository Writing Skills", vol. 6, 2007. http://ejite.isu.edu/Volume6/Drexler.pdf

[5] Kobayashi, M., "Using a group blog to enhance reflection of student teachers", Proceedings of Society for Information Technology and Teacher Education International Conference, 2008, págs. 3010-3012.

[6] Amorós-Poveda, Lucía, "Diseño de Weblogs en la Enseñanza" Edutec., núm. 24, diciembre del 2007. http://edutec.rediris.es/Revelec2/revelec24/lamoros/lamoros.htm

[7] Lee, K. "Creating Blogs in a Writing Course", Proceedings of Society for Information Technology and Teacher Education International Conference 2005, págs. 1986-1990.

[8] Seven Things You Should Know About Blogs, generado agosto 2005, Educause: Learning

iniative, consultado 21 febrero 2009, www.educause.ede/eli/

[9] Brescia, William F. Jr. \& Miller, Michael T.,"Whats it Worth? The Perceived Benefits of

Instructional Blogging"; Electronic Journal for the Integration of Technology in Education, Vol. 5 2006, pág. 44-52.

[10] D. M. Nagel; K. Anthony, "Writing therapy using new technologiesthe art of blogging", Journal of Poetry Therapy: The Interdisciplinary Journal of Practice, Theory, Research and Education, Volume 22, Issue 1, 2009, Pages 4145

[11] DeGennaro D, Brown TL; "Youth voices: connections between history, enacted culture and identity in a digital divide initiative". Cult Stud Sci Educ 4(1):13-39 (2009). 
[12] James B. McGee \& Michael Begg; "What medical educators need to know about "Web 2.0"'"; Medical Teacher; vol 30: 164-169 (2008)

[13] Walker, Rodrigo, "La Historia de los BLOGS", blog de Rodrigo Walker, generado 29 de Octubre de 2005, consultado enero 2009, http://www.rodrigowalker.cl/

[14] Blood, Rebecca. Weblogs: A History and Perspective, en el sitio Rebecca's Pocket. generado. 25/octubre /2006. Consultado el 2 febrero, 2009. http://www.rebeccablood.net/essays/weblog history.html.

[15] Dave Sifry, "State of the blogsphere/2008", Technorati.com, generado 5/abril/07, consultado 2/ene/2009.

[16] Dave Sifry, "State of the live Web"; Technorati.com, generado 5/abril/07; consultado 2/ene/2009. http://technorati.com/weblog/2007/04/328.html

[17] Vicente Torres-Zúñiga, "Blogs as an effective tool to teach and popularize physics: a case study" Latin American Physics Education, No. 2, vol. 3, May 2009.

[18] Jakob Nielsen,"Participation Inequality: Encouraging More Users to Contribute"; en Jakob Nielsen's Alertbox, http://www.useit.com/alertbox/participation inequality.html generado: 9/0ct/2006, consultado 2/mayo/2009.

[19] Alvarez Llera, Guillermo, "Tendencia de la matrícula femenina en la educación superior. Un cuarto de siglo. El caso de la carrera de medicina", Revista de la Facultad de Medicina UNAM, No. 004, (2006), http://chloe.dgsca.unam.mx/rfm/no49-4/RFM49406.pdf

[20] Encuesta sobre disponibilidad y uso de tecnología de información en los hogares, INEGI.gob.mx/EDUTIH consultado 7/06/2009.

\section{Para citar este artículo:}

TORRES, Vicente (2009) «¿Por qué las bitácoras electrónicas (blogs) se usan poco para estudiar ciencias físico-matemáticas?» [artículo en línea]. EDUTEC, Revista Electrónica de Tecnología Educativa. Núm. 29/ Julio 2009. [Fecha de consulta: $\mathrm{dd} / \mathrm{mm} / \mathrm{aa}$ ].

http://edutec.rediris.es/revelec2/revelec29/

ISSN 1135-9250. 